\title{
Identification of Digestive Enzyme Inhibitors from Ludwigia octovalvis (Jacq.) P.H.Raven
}

\author{
Dulce Morales $\mathbb{D}^{1},{ }^{1,2}$ Guillermo Ramirez, ${ }^{2}$ Armando Herrera-Arellano $\mathbb{D}^{1},{ }^{1}$ \\ Jaime Tortoriello $\oplus^{1},{ }^{2}$ Miguel Zavala $\oplus^{(},{ }^{3}$ and Alejandro Zamilpa $\oplus^{2}$ \\ ${ }^{1}$ Facultad de Medicina, Universidad Autónoma del Estado de Morelos, Cuernavaca 62350, Mexico \\ ${ }^{2}$ Centro de Investigación Biomédica del Sur, Instituto Mexicano del Seguro Social, Xochitepec 62790, Mexico \\ ${ }^{3}$ Departamento de Sistemas Biológicos, UAM-Xochimilco, Mexico City 04960, Mexico \\ Correspondence should be addressed to Alejandro Zamilpa; azamilpa_2000@yahoo.com.mx
}

Received 10 April 2018; Revised 6 June 2018; Accepted 26 June 2018; Published 16 July 2018

Academic Editor: Mohammed S. Razzaque

Copyright (C) 2018 Dulce Morales et al. This is an open access article distributed under the Creative Commons Attribution License, which permits unrestricted use, distribution, and reproduction in any medium, provided the original work is properly cited.

\begin{abstract}
Current antiobesity and antidiabetic tools have been insufficient to curb these diseases and frequently cause side effects; therefore, new pancreatic lipase and $\alpha$-glucosidase inhibitors could be excellent aids for the prevention and treatment of these diseases. The aim of this study was to identify, quantify, and characterize the chemical compounds with the highest degree of inhibitory activity of these enzymes, contained in a Ludwigia octovalvis hydroalcoholic extract. Chemical purification was performed by liquid-liquid separation and column chromatography. Inhibitory activities were measured in vitro, employing acarbose, orlistat, and a Camellia sinensis hydroalcoholic extract as references. For structural elucidation, Nuclear Magnetic Resonance was carried out, and High Performance Liquid Chromatography was used to quantify the compounds. For $\alpha$-glucosidases, L. octovalvis hydroalcoholic extract and its ethyl acetate fraction showed half-maximal Inhibitory Concentration $\left(\mathrm{IC}_{50}\right)$ values of 700 and $250 \mu \mathrm{g} / \mathrm{mL}$, for lipase, 480 and $718 \mu \mathrm{g} / \mathrm{mL}$, while $C$. sinensis showed 260 and $587 \mu \mathrm{g} / \mathrm{mL}$. The most active compounds were identified as ethyl gallate $\left(1, \mathrm{IC}_{50}\right.$ $832 \mu \mathrm{M})$ and gallic acid $\left(2, \mathrm{IC}_{50} 969 \mu \mathrm{M}\right)$; both displayed competitive inhibition of $\alpha$-glucosidases and isoorientin $\left(3, \mathrm{IC}_{50} 201 \mu \mathrm{M}\right)$, which displayed uncompetitive inhibition of lipase. These data could be useful in the development of a novel phytopharmaceutical drug.
\end{abstract}

\section{Introduction}

Although $\alpha$-glucosidase inhibitors such as acarbose and pancreatic lipase inhibitors such as orlistat are one of the safest antiobesity and antidiabetic drugs for weight loss and regulation of several metabolic and cardiovascular parameters in adults [1-3], these drugs have unpleasant gastrointestinal side effects that frequently result in therapy abandonment [4]. Therefore, it is necessary to continue the search for new alternatives to $\alpha$-glucosidase and pancreatic lipase inhibitors, with milder side effects and which contribute to the treatment of obesity and type 2 diabetes mellitus, in conjunction with current therapies.

Treatment with acarbose brings forth benefits in the regulation of $\mathrm{HbAlc}$, blood pressure, coagulation factors, thickness of the intimal layer of the carotid, endothelial dysfunction, serum glucose, and postprandial insulin [2], being especially useful in the treatment of diabetic patients with adequate baseline control but persistent postprandial hyperglycaemia [1]. While orlistat treatment not only produces a reduction in body weight and waist diameter, it also decreases HbAlc, blood pressure, and cholesterol [5], reducing the incidence of type 2 diabetes mellitus. In addition, orlistat is currently the only drug approved by the Food and Drug Administration (FDA) for the treatment of obesity in children [3]

Ludwigia octovalvis (Jacq.) P.H.Raven (Onagraceae) [syn: Jussiaea suffruticosa L., Jussiaea pubescens L., and Jussiaea angustifolia Lamk] is an helophyte, erect, herb with oblong-lanceolate leaves and solitary flowers of four yellow petals [6]. According to Mexican data, this species is not on a protection status [7]. Almost all parts of the plant 
have been reported as having several medicinal uses [8, 9], among them, the antidiabetic use by Mexican and Indian healers $[10,11]$, in which the boiled extract or the juice of the whole plant is used. Previous phytochemical studies have described the presence of flavonoids, phenolic acids, polyphenols, saponins, sterols, tannins, and triterpenoids [12-15] in different organs of this medicinal plant. Several pharmacological effects such as hypoglycaemic [8], antihyperglycaemic $[16,17]$, and antiproliferative, in 3T3-L1 adipocytes [18], have been described through various models. Moreover, the hydroalcoholic extract of $L$. octovalvis leaves was the most effective in the inhibition of $\alpha$-glucosidases and pancreatic lipase in a screening of 23 extracts of medicinal plants reported as traditional treatments for type 2 diabetes mellitus [10]. In addition, a report also exists on L. octovalvis antidiarrheal activity, probably mediated by regulation of gastrointestinal motility [19]; this activity could help reduce some of the side effects of intestinal enzyme inhibition, such as faecal urgency or abdominal pain.

The aim of this work was to isolate, identify, quantify, and characterize the compounds with the greatest inhibitory activity of $\alpha$-glucosidases and pancreatic lipase, in the hydroalcoholic extract of L. octovalvis leaves, through its bioassay-guided fractionation.

\section{Materials and Methods}

2.1. General. All chemicals were of analytical-reagent grade. Corn starch (S4126); 2,3-dimercapto-1-propanol tributyrate (DMPTB 97\%, 282413); 5,5'-dithiobis(2-nitrobenzoic acid) (DTNB $\geq 98 \%$, D8130); lipase from porcine pancreas (PPL type II, 100-500 units/mg, L3126); Triton X-100 (X100); SDS ( $\geq 98.5 \%$, L3771); glycerol ( $\geq 99.5 \%$, GE17-1325-01); DMSO ( $\geq 99.9 \%$, 547239); polyethylene glycol (PEG, 1546580); 2-aminoethyl diphenylborinate (97\%, D9754); isoorientin ( $\geq 98 \%$; I1536); and gallic acid $(\geq 97 \%, 27645)$ were purchased from Sigma-Aldrich (St. Louis, MO). Miscellaneous solvents were purchased from Merck KGaA (Darmstadt, Germany).

Orlistat (Lysthin, PsicoFarma, Mexico City) and acarbose (Sincrosa, Alpharma, Mexico City) were purified by silica chromatography and crystallized, to be used as positive controls for enzyme inhibition assays.

Thin layer chromatography (TLC) was performed using silica gel 60 RP-18 F254s aluminium sheets (105560, Merck $\mathrm{KGaA})$. TLC plates were analysed under UV light at 254 and $360 \mathrm{~nm}$, using the Natural Products-PEG reagent (NP-PEG; $1 \%$ methanolic solution of diphenylboryloxyethylamine followed by $5 \%$ ethanolic PEG) as chemical detection system [20].

Melting points were obtained on a Thermo Scientific IA9000 series melting point apparatus (Electrothermal, Essex, UK).

Nuclear Magnetic Resonance (NMR) ${ }^{1} \mathrm{H}(400 \mathrm{MHz})$ and NMR ${ }^{13} \mathrm{C}(100 \mathrm{MHz})$ spectra were obtained with Varian INOVA-400 equipment (Varian Co., Palo Alto, CA) using tetramethylsilane as internal standard.

2.2. Plant Material and Preparation of Extracts. Leaves of L. octovalvis were collected at Xochitepec, Morelos, Mexico $\left(18^{\circ} 47^{\prime} 40.70^{\prime \prime} \mathrm{N}, 99^{\circ} 11^{\prime} 49.27^{\prime \prime} \mathrm{W}\right)$, between September and October of 2012. A voucher of plant material was deposited under code number 34667 at the HUMO Herbarium in the Centro de Investigación en Biodiversidad y Conservación of the Autonomous University of the State of Morelos (Universidad Autónoma del Estado de Morelos-CIByC-UAEM, Morelos, Mexico).

Camellia sinensis (L.) Kuntze (Theaceae) commercial ground leaves, purchased at a Japanese specialty store (Yamamotoyama, Pomona, CA), was used as a positive vegetal control. Plant names were checked and updated with the online website http://www.theplantlist.org. [21].

Fresh leaves of L. octovalvis were washed and dried under dark conditions at room temperature and then milled to 4-6 $\mathrm{mm}$. Ground material ( $1 \mathrm{~kg})$ was extracted (1:10 ratio, w/v) with a $60 \%$ ethanol aqueous solution at $25^{\circ} \mathrm{C}$ for $24 \mathrm{~h}$. The liquid extract was paper-filtered, concentrated in a rotary evaporator Laborota 4000 (Heidolph, Schwabach, Germany) under reduced pressure at $50^{\circ} \mathrm{C}$, and freeze-dried to obtain $337 \mathrm{~g}$ of brown powder (32.4\% yield). This dry extract (LoHAE) was stored at $4^{\circ} \mathrm{C}$ until its pharmacological and phytochemical analysis. C. sinensis hydroalcoholic extract (CsHAE) was identically prepared.

2.3. Fractionation of LoHAE and Purification of Active Fractions. One hundred and ninety grams of LoHAE was subjected to a liquid-liquid separation process using water and ethyl acetate. The solvent of both fractions was eliminated by low pressure distillation to obtain an organic fraction (LoEAF) and an aqueous fraction (LoAqF).

The less polar fraction (LoEAF, $25 \mathrm{~g}$ ) was subjected to a chromatographic silica gel 60 column (109385, Merck KGaA) using dichloromethane/methanol gradient system as mobile phase, to give 69 samples of $150 \mathrm{~mL}$ each. The separation process was monitored by TLC and all the samples were grouped into 20 final fractions. The most representative fractions (yields $\geq 5 \%$; C1F1-C1F6) were subjected to both assays.

The active fractions C1F4 and C1F6 were fractionated using column chromatography with silica gel LiChroprep $^{\circledR}$ RP-18 (113900, Merck KGaA) and a mixture of water/acetonitrile. All the fractions were analysed by TLC and the samples with similar chemical composition were grouped.

From C1F4 (186 mg), 10 final fractions were obtained, of which $\mathrm{C} 2 \mathrm{~F} 1$ produced a white precipitate, which was found to be a pure compound by TLC and High Performance Liquid Chromatography (HPLC).

From C1F6 (1.1 g), 19 final fractions were obtained; the most representative (yields $\geq 5 \%$ ) were $\mathrm{C} 3 \mathrm{~F} 1, \mathrm{C} 3 \mathrm{~F} 2, \mathrm{C} 3 \mathrm{~F} 3$, and $\mathrm{C} 3 \mathrm{~F} 4$. Fraction $\mathrm{C} 3 \mathrm{~F} 3$ was purified, obtaining fractions C4F1, C4F2, C4F3, C4F4, C4F5, and C4F6. Fraction C4F4 produced an orange/yellow precipitate (C4F4-P, $12 \mathrm{mg}$ ). All these fractions (see Scheme 1) were subjected to the pharmacological assay.

2.4. HPLC Analysis. HPLC analysis was performed on a chromatographic system equipped with a Waters Alliance Separation Module (2695, Waters Corporation, Milford, MA) 


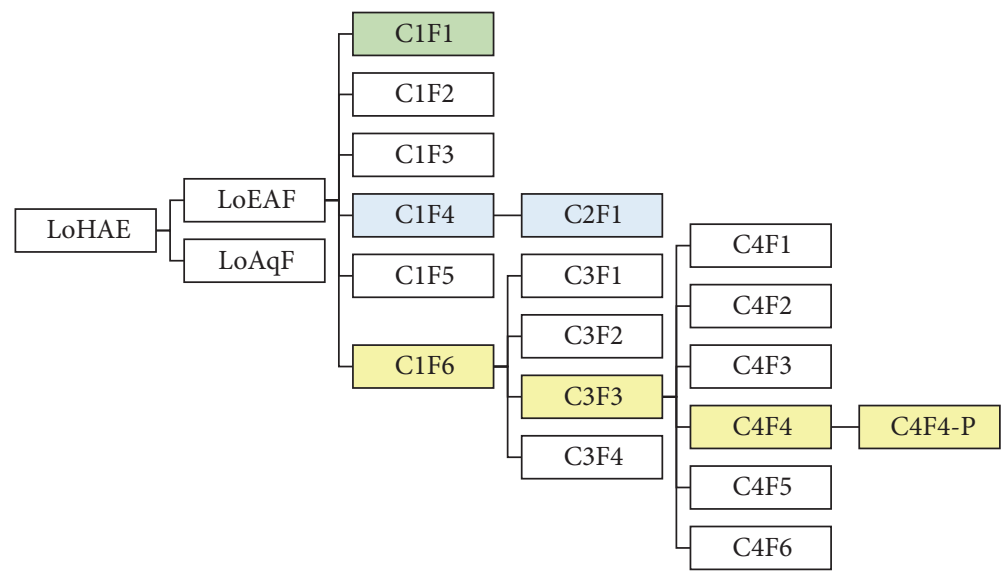

Scheme 1: Fractionation of L. octovalvis hydroalcoholic extract (LoHAE). The isolation process of the active compounds is illustrated by colors: green for ethyl gallate, blue for gallic acid, and yellow for isoorientin.

and a photodiode array detector (2996, Waters Corporation), employing Empower Pro software (Waters Corporation). Separation was carried out using a Supelcosil LC-F HPLC column (59158, Supelco, Bellefonte, PA). The mobile phase consisted of a mixture of trifluoroacetic acid solution (solvent $\mathrm{A}, 0.5 \%$ ) and acetonitrile (solvent $\mathrm{B}$ ) with the following ratios: $\mathrm{A}: \mathrm{B}=100: 0$ (0-1 min); 95:5 (2-3 min); 70:30 (4-7 min); 50:50 (8-22 min); 20:80 (23 min); 0:100 (24-26 min); 100:0 (27-30 $\mathrm{min})$. The sample injection volume was $10 \mathrm{~mL}$ with a 0.9 $\mathrm{mL} / \mathrm{min}$ flow rate during $30 \mathrm{~min}$. The detection wavelength was $190-600 \mathrm{~nm}$.

Quantification of the isolated compounds was achieved using calibration curves and LoHAE or LoEAF HPLC analysis. The calibration curve was made using ascendant concentrations $(25,50,100$, and $200 \mu \mathrm{g} / \mathrm{mL})$ of the isolated compounds, which were injected by triplicate at $10 \mu \mathrm{L}$ in the previously described HPLC method. A chromatographic profile of each concentration was obtained at 254 or $360 \mathrm{~nm}$ wavelength and data on area under curve peak were used to obtain the respective straight-line equations.

2.5. Enzymatic Inhibition Assays. Pancreatic lipase inhibition assay was previously reported [22]. Briefly, the absorbance of a mixture of DTNB $0.2 \mathrm{mM}$, DMPTB $0.8 \mathrm{mM}, \mathrm{NaCl}$ $0.1 \mathrm{M}, \mathrm{CaCl} 22 \mathrm{mM}$, Triton X-100 0.04\%, porcine lipase 65 $\mu \mathrm{g} / \mathrm{mL}$, and the sample (dissolved in DMSO and water) at $0.25 \mathrm{mg} / \mathrm{mL}$ was followed with a Thermo Scientific Genesys 20 Visible Spectrophotometer (Fisher Scientific, 4001000, Hampton, NH) at $412 \mathrm{~nm}$ every $20 \mathrm{~s}$ for five minutes and plotted (Excel, Microsoft) to obtain initial velocity value. The lipase was prepared as a stock at $10 \mathrm{mg} / \mathrm{mL}$ in Tris- $\mathrm{HCl} 25$ $\mathrm{mM} \mathrm{pH} 6.2$ with $0.1 \mathrm{M} \mathrm{NaCl}$, SDS $2 \mathrm{mM}$, and $250 \mu \mathrm{L} / \mathrm{mL}$ of glycerol. A control assay without substrate was carried out to discard nonspecific reactions with DTMB. All reactions were tested by triplicate.

The $\alpha$-glucosidase assay was previously reported [10]. In brief, corn starch $(4 \mathrm{mg} / \mathrm{mL})$ was digested by crude enzyme at $37^{\circ} \mathrm{C}$ during 10 minutes in a phosphate buffer $\mathrm{pH} 7$ solution at a sample concentration of $0.6 \mathrm{mg} / \mathrm{mL}$ (dissolved in DMSO and water). Subsequently, released glucose was quantified by a glucose oxidase-based clinical reagent with the GOD-POD Trinder kit (Spinreact, Girona, Spain) following manufacturer's directions. All tests were performed in quadruplicate. Crude enzyme was obtained directly from healthy Wistar rats (12 h fasting). The small intestine was flushed several times with ice-cold isotonic buffer $\mathrm{pH} 7$ and after the scraping of the mucosa, it was homogenized and stored at $-20^{\circ} \mathrm{C}$. Animal care and management were carried out under the guidelines of Mexican Official Standard NOM-062-ZOO-1999.

For both assays, percentage of inhibitions was calculated as the residual enzymatic activity of the negative control (DMSO and water) by using

$$
\% \text { inhibition }=100-\left(\frac{\text { Absorbance }_{\text {sample }}}{\text { Absorbance }_{\text {control }}} \times 100\right)
$$

Concentrations of extracts resulting in 50\% inhibition of enzyme activity ( $\mathrm{IC}_{50}$ values) were determined graphically, quantifying enzymatic activities at ascendant concentrations of each sample $(6-3600 \mu \mathrm{g} / \mathrm{mL}$ for $\alpha$-glucosidases and $5-2500 \mu \mathrm{g} / \mathrm{mL}$ for pancreatic lipase). The logarithm of the concentration was plotted on the $\mathrm{x}$-axis and the percentage of enzymatic inhibitory activity on the y-axis to obtain a semilogarithmic graphic.

The type of inhibition was determined quantifying the activity with and without inhibitor at different substrate concentrations $(5-0.35 \mathrm{mg} / \mathrm{mL}$ for $\alpha$-glucosidases and $0.05-0.2 \mu \mathrm{g} / \mathrm{mL}$ for pancreatic lipase) and comparing Lineweaver-Burk plots (inverse substrate concentration [S] and inverse reaction velocity V). In the case of the determination of $\alpha$-glucosidase type of inhibition, the substrate was changed from corn starch to maltodextrin (MD100, Luzhou Bio-Chem Technology Co., Shandong, China), in order to have greater uniformity in the reaction.

Michaelis-Menten constant $\left(\mathrm{K}_{\mathrm{m}}\right)$ and apparent $\mathrm{K}_{\mathrm{m}}$ $\left(\mathrm{K}_{\mathrm{m}}{ }^{\text {app }}\right)$ were obtained analysing the Lineweaver-Burk plots. These values allowed to obtain the inhibition constant $\left(\mathrm{K}_{\mathrm{i}}\right)$ 
TABLE 1: Enzyme inhibition of hydroalcoholic extract, fractions, and compounds isolated from L. octovalvis leaves.

\begin{tabular}{|c|c|c|}
\hline \multirow[b]{2}{*}{ Sample } & \multicolumn{2}{|c|}{ Inhibition percentage } \\
\hline & $\begin{array}{c}\alpha \text {-glucosidases } \\
0.6 \mathrm{mg} / \mathrm{mL}\end{array}$ & $\begin{array}{c}\text { Pancreatic lipase } \\
0.25 \mathrm{mg} / \mathrm{mL}\end{array}$ \\
\hline Acarbose & $50.0 \pm 1.6 *$ & N.A. \\
\hline Orlistat & N.A. & $50.0 \pm 2.6 * *$ \\
\hline CsHAE & $80.8 \pm 1.1$ & $34.8 \pm 2.5$ \\
\hline LoHAE & $58.9 \pm 5.7$ & $23.6 \pm 2.5$ \\
\hline LoEAF & $82.8 \pm 3.6$ & $31.2 \pm 1.9$ \\
\hline LoAqF & $76.8 \pm 1.9$ & $15.6 \pm 2.5$ \\
\hline C1F1 (ethyl gallate) & $98.4 \pm 2.0$ & $23.2 \pm 3.0$ \\
\hline $\mathrm{ClF} 2$ & $60.1 \pm 5.5$ & $22.5 \pm 3.6$ \\
\hline $\mathrm{C} 1 \mathrm{~F} 3$ & $39.9 \pm 5.6$ & $4.3 \pm 3.5$ \\
\hline $\mathrm{C} 1 \mathrm{~F} 4$ & $98.9 \pm 1.6$ & $20.0 \pm 2.3$ \\
\hline $\mathrm{C} 1 \mathrm{~F} 5$ & $84.2 \pm 5.3$ & $28.2 \pm 2.7$ \\
\hline C1F6 & $79.8 \pm 3.8$ & $45.3 \pm 0.6$ \\
\hline C2F1 (gallic acid) & $98.9 \pm 0.6$ & N.A. \\
\hline $\mathrm{C} 3 \mathrm{~F} 1$ & N.A. & $10.9 \pm 0.3$ \\
\hline $\mathrm{C} 3 \mathrm{~F} 2$ & N.A. & $29.3 \pm 3.6$ \\
\hline $\mathrm{C} 3 \mathrm{~F} 3$ & N.A. & $43.5 \pm 4.3$ \\
\hline $\mathrm{C} 3 \mathrm{~F} 4$ & N.A. & $36.4 \pm 4.0$ \\
\hline $\mathrm{C} 4 \mathrm{~F} 1$ & N.A. & $41.4 \pm 3.2$ \\
\hline $\mathrm{C} 4 \mathrm{~F} 2$ & N.A. & $16.6 \pm 4.5$ \\
\hline $\mathrm{C} 4 \mathrm{~F} 3$ & N.A. & $45.8 \pm 5.1$ \\
\hline C4F4-P (isoorientin) & N.A. & $55.1 \pm 3.1$ \\
\hline C4F5 & N.A. & $53.5 \pm 3.7$ \\
\hline C4F6 & N.A. & $49.1 \pm 3.8$ \\
\hline Luteolin & $66.3 \pm 5.6$ & N.A. \\
\hline
\end{tabular}

The data is indicated as the mean \pm standard deviation.

N.A. $=$ not analysed; $*$ evaluated at $5.8 \mu \mathrm{M} ; * *$ evaluated at $1.6 \mu \mathrm{M}$.

for competitive inhibitors using (2), where [I] represents inhibitor concentration.

$$
K_{m}^{a p p}=K_{m}\left(1+\frac{[I]}{K_{i}}\right)
$$

2.6. Statistical Analysis. Experimental enzymatic inhibition activity values are expressed as the percentage of inhibition. All biological assays were analysed by ANOVA followed by a Tukey post-test, with statistical differences established at $\mathrm{p}<0.05$, using the SPSS10.0 program.

\section{Results}

3.1. Fractionation of Hydroalcoholic Extract. The liquid-liquid separation of LoHAE produced LoAqF (82.3\% yield; 156 g) and LoEAF $(17.1 \% ; 32 \mathrm{~g})$. Samples of these materials and CsHAE were analysed in the in vitro models of enzyme inhibition at $0.6 \mathrm{mg} / \mathrm{mL}$ in the case of $\alpha$-glucosidases and at $0.25 \mathrm{mg} / \mathrm{mL}$ in the case of pancreatic lipase (see Table 1).

LoHAE inhibited the $\alpha$-glucosidases by $58.9 \%$ and the pancreatic lipase by $23.6 \%$, while CsHAE produced an $80.8 \%$ inhibition of $\alpha$-glucosidases and $34.8 \%$ of pancreatic lipase.
The organic fraction, LoEAF, had more inhibitory activity than LoAqF fraction or LoHAE extract in both assays, with an $82.8 \%$ inhibition of $\alpha$-glucosidases and $31.2 \%$ inhibition of pancreatic lipase.

High Performance Liquid Chromatography spectra analysis of LoEAF (see Figure 1(a)) indicated the presence of flavonoids and organic acids [20,23]. The first chromatography separation of LoEAF afforded 60 fractions, which were grouped in six (C1F1-C1F6), where $\mathrm{C} 1 \mathrm{~F} 1$ and $\mathrm{C} 1 \mathrm{~F} 4$ fractions displayed the highest inhibitory effect on $\alpha$-glucosidases, while C1F6 was the most active for lipase (see Table 1).

3.2. Identification of $\alpha-$ Glucosidase Inhibitors. Fraction $\mathrm{C} 1 \mathrm{~F} 1$ produced a white precipitate (melting point $=160^{\circ} \mathrm{C}$ ) that was analysed by HPLC (see Figure 1(b)) and its chemical structure was corroborated by comparison of spectroscopic ${ }^{1} \mathrm{H}$ and ${ }^{13} \mathrm{C}$ NMR data (see Table 2 and Figures S1-S2 in the Supplementary Material) indicating that this compound corresponds to ethyl gallate [24] (see Figure 2).

Fraction $\mathrm{C} 1 \mathrm{~F} 4$ produced Fraction $\mathrm{C} 2 \mathrm{~F} 1$, which also produced a white precipitate (melting point $=260^{\circ} \mathrm{C}$ ). HPLC, UV spectra (see Figures 1(c)-1(d)), and spectroscopic ${ }^{1} \mathrm{H}$ 


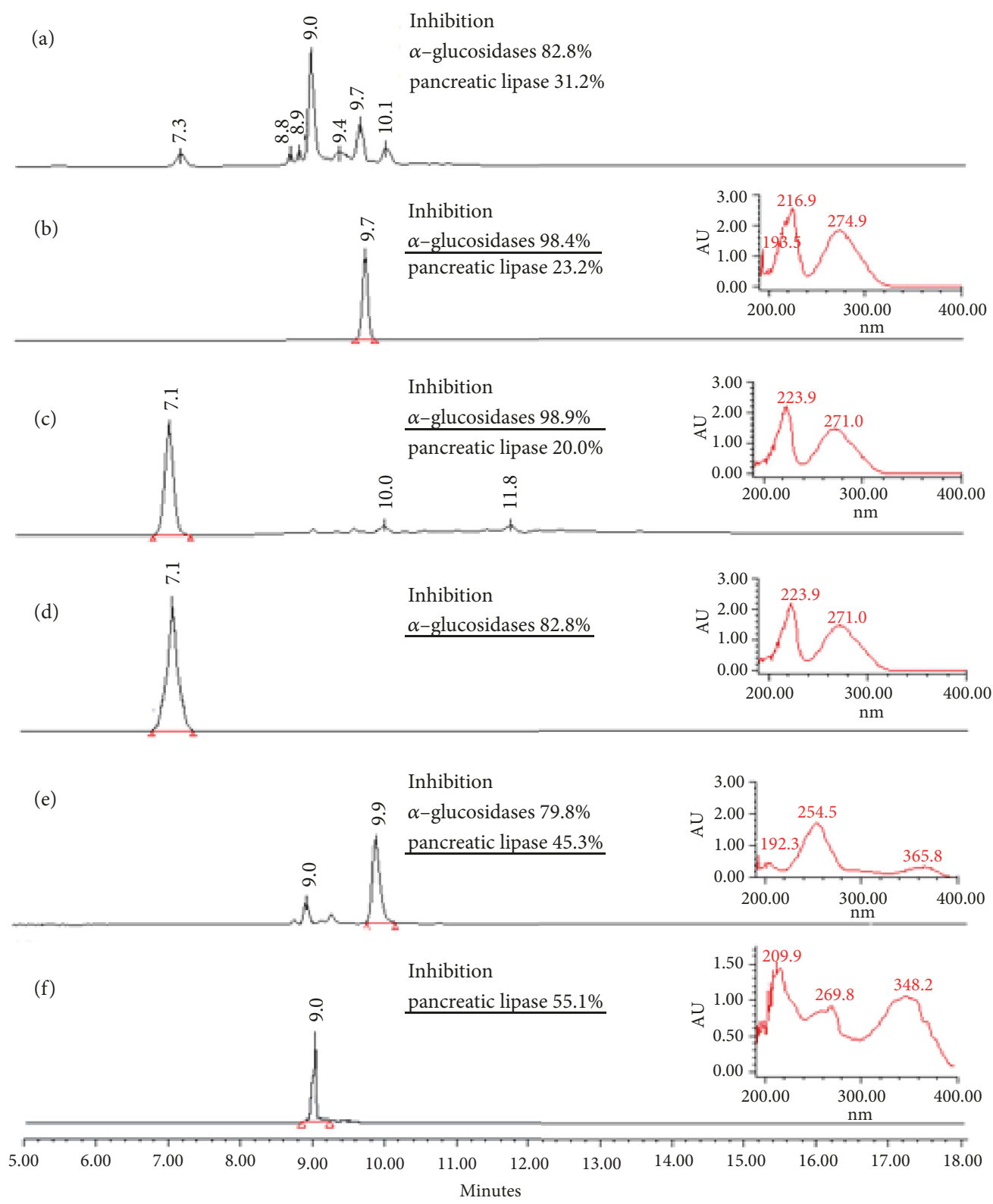

Figure 1: High Performance Liquid Chromatography chromatograms, UV spectra (at $270 \mathrm{~nm}$ ), and enzymatic inhibition percentage of different L. octovalvis fractions. (a) Ethyl acetate fraction LoEAF. (b) Fraction C1F1. (c) Fraction C1F4. (d) Fraction C2F1. (e) Fraction C1F6. (f) Fraction C4F4-P.<smiles>[R]OC(=O)c1cc(O)c(O)c(O)c1</smiles>

$\mathrm{R}$

ethyl gallate $-\mathrm{CH}_{2}-\mathrm{CH}_{3}$ gallic acid $-\mathrm{H}$<smiles>O=c1cc(-c2ccc(O)c(O)c2)oc2cc(O)c(C3OC(CO)C(O)C(O)C3O)c(O)c12</smiles>

Figure 2: Chemical structure of the most active compounds identified in L. octovalvis hydroalcoholic extract. 
TABLE 2: Nuclear Magnetic Resonance (NMR) ${ }^{13} \mathrm{C}$ data of the compounds contained in C1F1 and C4F4-P fractions and previously reported data for ethyl gallate and isoorientin.

\begin{tabular}{|c|c|c|c|c|}
\hline \multirow{2}{*}{ Carbon position } & \multicolumn{4}{|c|}{ Chemical shifts (ppm) } \\
\hline & Ethyl gallate & $\mathrm{C} 1 \mathrm{~F} 1$ & Isoorientin & C4F4-P \\
\hline 1 & 121.9 & 121.95 & - & - \\
\hline 2 & 110.1 & 110.18 & 163.44 & 163.61 \\
\hline 3 & 146.4 & 146.57 & 102.38 & 102.78 \\
\hline 4 & 139.6 & 139.79 & 181.45 & 181.84 \\
\hline 5 & 146.4 & 146.57 & 160.59 & 160.67 \\
\hline 6 & 110.1 & 110.18 & 108.88 & 108.86 \\
\hline 7 & 168.6 & 168.69 & 163.44 & 163.23 \\
\hline 8 & 61.6 & 61.81 & 93.73 & 93.46 \\
\hline 9 & 14.6 & 14.73 & 156.27 & 156.16 \\
\hline 10 & - & - & 102.79 & 103.38 \\
\hline $1^{\prime}$ & - & - & 121.56 & 121.4 \\
\hline $2^{\prime}$ & - & - & 118.82 & 118.95 \\
\hline $3^{\prime}$ & - & - & 116.00 & 116.02 \\
\hline $4^{\prime}$ & - & - & 150.44 & 149.68 \\
\hline $5^{\prime}$ & - & - & 145.95 & 145.72 \\
\hline $6^{\prime}$ & - & - & 112.92 & 113.29 \\
\hline $1^{\prime \prime}$ & - & - & 73.18 & 73.02 \\
\hline $2^{\prime \prime}$ & - & - & 70.50 & 70.60 \\
\hline $3^{\prime \prime}$ & - & - & 78.95 & 78.93 \\
\hline $4^{\prime \prime}$ & - & - & 70.19 & 70.17 \\
\hline $5^{\prime \prime}$ & - & - & 81.35 & 81.56 \\
\hline $6^{\prime \prime}$ & - & - & 61.34 & 61.48 \\
\hline
\end{tabular}

NMR analysis (see Figure S3 in the Supplementary Material) indicated that this fraction corresponds to gallic acid [24] (see Figure 2).

According to HPLC analysis (see Figure S4 in the Supplementary Material), LoHAE and LoEAF contained, respectively, $0.7 \%$ and $4.6 \%$ of ethyl gallate and $1.9 \%$ and $2.5 \%$ of gallic acid.

3.3. Identification of Pancreatic Lipase Inhibitors. Fraction C1F6 was analysed by HPLC where several kinds of organic constituents were observed (see Figure 1(e)). Subsequent chromatographic separations of this fraction, followed by inhibitory activity evaluation (see Table 1), allowed us to obtain 11 fractions (see Scheme 1) with different chemical profiles but similar inhibitory activities. The most active fraction, C4F4-P (melting point $=245^{\circ} \mathrm{C}$ ), was evaluated by HPLC (see Figure 1(f)) and elucidated by ${ }^{1} \mathrm{H}$ NMR, ${ }^{13} \mathrm{C}$ NMR, and two-dimensional NMR spectroscopy experiments (see Table 2 and Figures S5-S9 in the Supplementary Material) and corresponded to isoorientin [25] (see Figure 2). The other active fractions are constituted mainly by flavonoids and other nonidentified compounds.

According to HPLC analysis (see Figure S4 in the Supplementary Material), LoHAE and LoEAF contained $0.2 \%$ and $0.1 \%$ of isoorientin, respectively.

\subsection{Calculating Half-Maximal Inhibitory Concentration and Determining Type of Inhibition}

3.4.1. $\alpha$-Glucosidases. All graphs corresponding to concentration-response curves in the $\alpha$-glucosidase inhibition model are shown (see Figure 3). CsHAE displayed a value of half-maximal Inhibitory Concentration $\left(\mathrm{IC}_{50}\right) 260 \mu \mathrm{g} / \mathrm{mL}$, while LoHAE produced $\mathrm{IC}_{50} 700 \mu \mathrm{g} / \mathrm{mL}$. Ethyl gallate $(\mathrm{C} 1 \mathrm{~F} 1)$ and gallic acid (C2F1) $\mathrm{IC}_{50}$ values were $832 \mu \mathrm{M}$ and $969 \mu \mathrm{M}$, respectively. Luteolin (Sigma, L9283) was used as a naturally occurring reference displaying an $\mathrm{IC}_{50}=1257.7 \mu \mathrm{M}$.

Both compounds, ethyl gallate and gallic acid, make $\mathrm{K}_{\mathrm{m}}$ (intersection $\mathrm{x}$-axis) increase, but maximal velocity $\left(\mathrm{V}_{\max }\right.$; intersection $y$-axis) remains the same, as expected for a competitive enzymatic inhibition (see Figures 4(a)-4(b)).

For the particular conditions of this assay, the calculated $\mathrm{K}_{\mathrm{m}}$ was $460 \pm 3 \mu \mathrm{M}$. In the case of $\mathrm{K}_{\mathrm{i}}$ constants, for ethyl gallate at $625 \mu \mathrm{M}, \mathrm{K}_{\mathrm{i}}=636 \mu \mathrm{M}$ and at $1250 \mu \mathrm{M}, \mathrm{K}_{\mathrm{i}}=315 \mu \mathrm{M}$; for gallic acid at $625 \mu \mathrm{M}, \mathrm{K}_{\mathrm{i}}=436 \mu \mathrm{M}$ and at $1250 \mu \mathrm{M}, \mathrm{K}_{\mathrm{i}}=$ $208 \mu \mathrm{M}$.

3.4.2. Pancreatic Lipase. The positive vegetal control, $C$. sinensis, displayed an $\mathrm{IC}_{50}$ value of $587 \mu \mathrm{g} / \mathrm{mL}$, while LoHAE displayed $480 \mu \mathrm{g} / \mathrm{mL}$, LoEAF $718 \mu \mathrm{g} / \mathrm{mL}$, and isoorientin 201 $\mu \mathrm{M}$ (see Figure 5). 


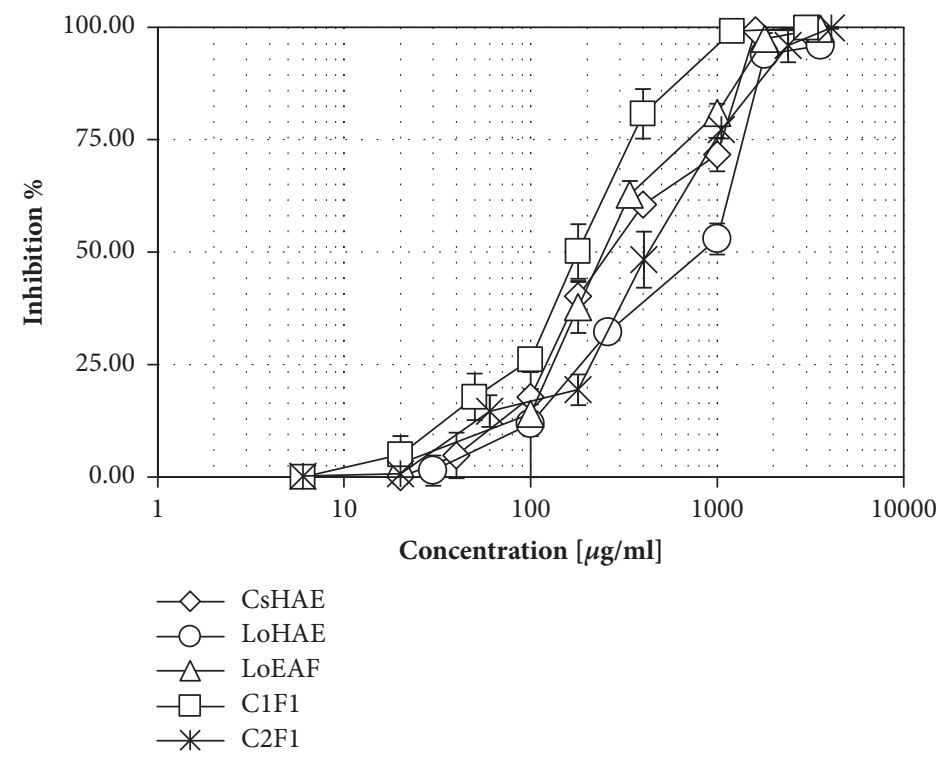

FIGURE 3: Concentration-response graphics for half-maximal Inhibitory Concentration $\left(\mathrm{IC}_{50}\right.$ ) determination of CsHAE, LoHAE, LoEAF, $\mathrm{C} 1 \mathrm{~F} 1$ (isolated ethyl gallate), and C2F1 (isolated gallic acid), in the inhibition model of $\alpha$-glucosidases. X-axis values are presented in $\mu \mathrm{g} / \mathrm{mL}$ (real values are logarithmic). The error bars represent the standard deviation of 2 measurements in four separate sample runs $(\mathrm{n}=8)$.

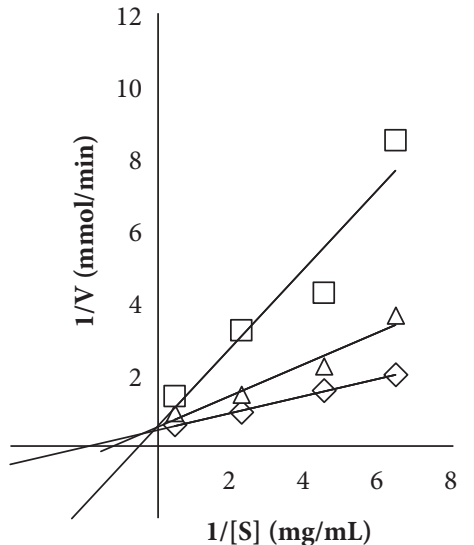

$\diamond \mathrm{C} 1 \mathrm{~F} 10 \mu \mathrm{M}$

$\triangle \mathrm{C} 1 \mathrm{~F} 1625 \mu \mathrm{M}$

C1F1 $1250 \mu \mathrm{M}$

(a)

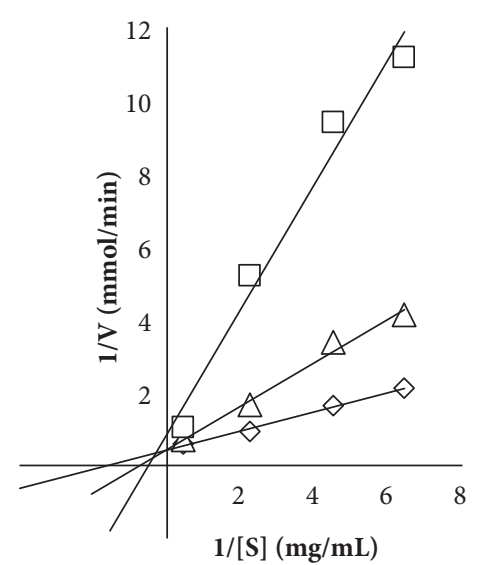

$\diamond \mathrm{C} 2 \mathrm{~F} 10 \mu \mathrm{M}$

$\triangle \mathrm{C} 2 \mathrm{~F} 1625 \mu \mathrm{M}$

$\mathrm{C} 2 \mathrm{~F} 11250 \mu \mathrm{M}$

(b)

FIGURE 4: Determination of enzymatic inhibition type by Lineweaver-Burk plots curves in the $\alpha$-glucosidase inhibition model. (a) C1F1 (isolated ethyl gallate). (b) C2F1 (isolated gallic acid).

As observed in the graph (see Figure 6), isoorientin changed both $\mathrm{V}_{\max }$ and $\mathrm{K}_{\mathrm{m}}$ (both intersection axes), so it produced uncompetitive enzymatic inhibition of pancreatic lipase [26].

\section{Discussion}

According to several studies, postprandial hyperglycaemia periods, even the relative short-lasting ones, contribute to the development of chronic diabetes complications even more than basal hyperglycaemia [27]. Moreover, the management of postprandial hyperglycaemia is more difficult to achieve than basal glucose control, even with a satisfactory HbAlc control [28], making it one of the main problems in diabetes treatment [1]. Of all the available antidiabetic drugs, $\alpha$-glucosidase inhibitors are currently the most effective and safest for postprandial glycaemia control as well as intraday and interday glucose fluctuation [29]. On the other hand, changes have also been found in postprandial lipaemia and plasma free fatty acids (fasting and postprandial) in patients with type 2 diabetes mellitus, which increase macrovascular damage [30] and also may cause $\beta$-cell dysfunction [31]. 


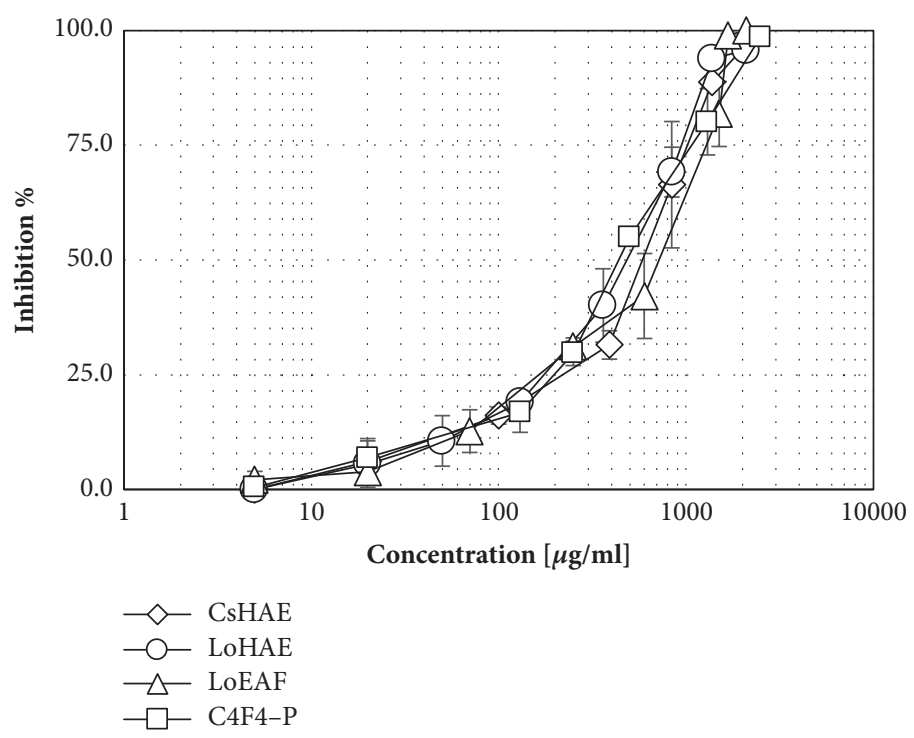

FIGURE 5: Concentration-response graphics for half-maximal Inhibitory Concentration $\left(\mathrm{IC}_{50}\right)$ determination of CsHAE, LoHAE, LoEAF, and C4F4-P (isolated isoorientin) in the inhibition model of pancreatic lipase. $\mathrm{x}$-axis values are represented in $\mu \mathrm{g} / \mathrm{mL}$ (real values are logarithmic). The error bars represent the standard deviation of 2 measurements in three separate sample runs $(n=6)$.

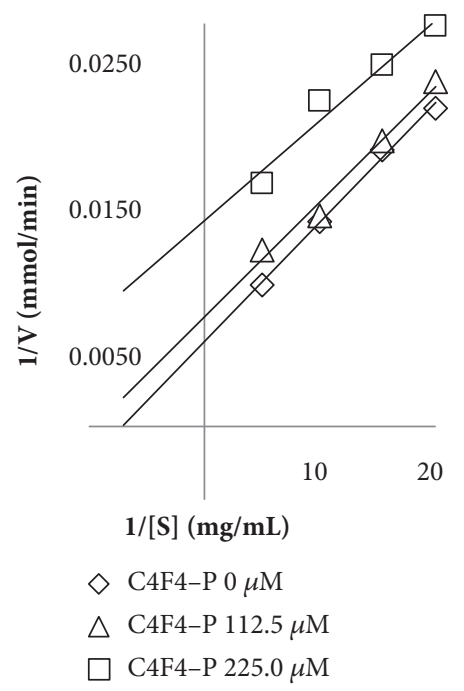

FIGURE 6: Determination of enzymatic inhibition type of C4F4-P (isolated isoorientin) by Lineweaver-Burk plots curves in the pancreatic lipase inhibition model.

What is worse, when high levels of free fatty acids couple with glycaemic fluctuations, they not only cause endothelium damage [32], but also have a prooxidant effect on pancreatic $\beta$ cells, leading to $\beta$-cell exhaustion [33]; this phenomenon has been called glucolipotoxicity. However, it has been shown that orlistat, a lipase inhibitor, significantly improves postprandial lipaemia and free fatty acid levels in nondiabetic hyperlipidemic subjects and also in overweight type 2 diabetic patients $[34,35]$.

L. octovalvis hydroalcoholic extract has the advantage of displaying both $\alpha$-glucosidase and pancreatic lipase inhibition activities. This is the first time that these mechanism modes are described for this species. Besides L. octovalvis is an interesting option as antidiabetic because it was described as innocuous according to the OECD [12].

In this study, the concentration of low and intermediate polarity compounds contained in LoEAF considerably increased the inhibition of both digestive enzymes, although an increase of $\alpha$-glucosidase inhibition was also observed in LoAqF, indicating the presence of other polar compounds with high inhibitory activity of these enzymes. Nevertheless, according to HPLC quantitative analysis, the bipartition process successfully increased the concentration of the two $\alpha$-glucosidase inhibitors in the organic fraction. Therefore, it would be proper to design an extraction or separation method that concentrates these polyhydroxy benzoic acid derivatives. Although gallic acid has been previously described for L. octovalvis [15], this is the first time that its ethyl ester derivative (ethyl gallate) is identified and related to the biological activity. The inhibition of these compounds using intestinal rat enzyme and starch as substrate was found higher than that produced by the natural product reference luteolin $\left(\mathrm{IC}_{50} \approx 1257.7 \mu \mathrm{M}\right)$ which has been described as good inhibitor of $\alpha$-glucosidases [36-38].

The inhibitory activity of carbohydrate degrading enzymes by gallic acid and its esters, such as ethyl gallate, has been described with inconsistent results. According to some authors, gallic acid showed very low or no inhibitory activity on porcine and Bacillus sp. $\alpha$-amylase on rat and Saccharomyces sp. $\alpha$-glucosidases on rat maltase [39-43]. However, other studies report that this compound shows high inhibitory activity on rat $[42,44]$ and yeast $\alpha$-glucosidases [45] and on porcine $\alpha$-amylase [43]. Moreover it was found that gallic acid was able to inhibit mouse, rabbit, and rat sucrose as well as rat maltase and trehalase [46]. Furthermore, the $\mathrm{IC}_{50}$ values of gallic acid and ethyl gallate in the inhibition of maltase $(390 \mu \mathrm{M}, 415 \mu \mathrm{M})$ and sucrase 
$(130 \mu \mathrm{M}, 660 \mu \mathrm{M})$ in rat were considered significantly high values [40].

This inconsistency of results could be due in part to the diversity of enzymes and substrates used for these tests; it has been shown that the effect of $\alpha$-glucosidase inhibitors varies according to the origin of the enzymes and the type of substrate used. According to Oki et al. [47], to perform the best evaluation of possible $\alpha$-glucosidase inhibitors for clinical use, mammalian enzymes and natural substrates of each type of enzyme should be used. Results of this work strengthen the hypothesis that these phenolic compounds (gallic acid and ethyl gallate) could be active in the inhibition of human $\alpha$-glucosidases.

In this study, ethyl gallate and gallic acid displayed a competitive enzymatic inhibition, in which the inhibitor competes directly with the substrate for the binding site in the active site of the enzyme [27]. This is one of few studies in which the enzymatic inhibition type and $\mathrm{K}_{\mathrm{i}}$ of naturally occurring compounds are described on digestive enzymes [48].

In the case of lipase inhibition, the most active compounds were enriched in the organic LoEAF fraction. Further purification by silica chromatography allowed us to obtain a C-glycosylated flavone: isoorientin [13]. This flavonoid displayed the best inhibitory effect and most of the fractions that produced significant activity (C1F6, C4F3, C4F5, and C4F6) contain high levels of isoorientin.

These kinds of C-glycosylated flavonoids have shown high inhibition of pancreatic lipase and according to some authors, glycosylation in position C-8 seems to significantly increase this biological activity [42-44].

Considering that it is desirable to have reference compounds to standardize a phytopharmaceutical drug, isoorientin could fulfil this purpose in L. octovalvis extracts with pancreatic lipase inhibitory action.

According to a toxicity analysis of this plant, an alcoholic extract from $L$. octovalvis did not display acute toxicity in mice when it was tested at $5000 \mathrm{mg} / \mathrm{kg}$ nor subacute toxicity at $400 \mathrm{mg} / \mathrm{kg}$ during 28 days [12], which is essential in the development of new phytomedicines. Furthermore, it is worth mentioning that the findings of the present study validate the traditional use of this plant species in the treatment of diabetes and also as an alternative to synthetic drugs such as acarbose and orlistat, since L. octovalvis displayed at least two mechanisms of antidiabetic and antiobesity action, which are synergistic and complementary.

Although none of the L. octovalvis treatments were as potent as the reference drugs, there are reports where in vitro digestive enzyme inhibition of naturally occurring compounds is lower than acarbose or orlistat but when tested on in vivo models, they produced similar pharmacological activities $[49,50]$.

\section{Conclusions}

The chemical separation of L. octovalvis hydroalcoholic extract which is bioactive in $\alpha$-glucosidase and pancreatic lipase inhibition allowed the identification and pharmacological characterization of one flavone (isoorientin) with considerable inhibitory effect of pancreatic lipase and two isolated compounds with high inhibitory effect of the $\alpha$-glucosidases (ethyl gallate and gallic acid). These findings bear out one of the possible mechanisms of action by which this medicinal plant could help in the prevention and treatment of type 2 diabetes and obesity; therefore, these data will be useful in the development of a potential novel phytomedicine.

\section{Data Availability}

The data used to support the findings of this study are available from the corresponding author upon request.

\section{Conflicts of Interest}

The authors declare that there are no conflicts of interest regarding the publication of this paper.

\section{Acknowledgments}

The authors are indebted to Gabriel Flores, curator of HUMO Herbarium, for his support identifying L. octovalvis and also to Ernesto Sánchez for his technical spectroscopic support of NMR. The technical assistance of Arturo Pérez and Jonathan Orduño is also acknowledged. This work was supported by the Consejo Nacional de Ciencia y Tecnología (CONACYT) [Grant no. 598815] and CIS-IMSS [(FIS/IMSS/PROT/MD17/1693); Grant no. 99187804]. Alejandro Zamilpa thanks Fundación IMSS.

\section{Supplementary Materials}

Figure S1: Nuclear Magnetic Resonance (NMR) 1H spectrum of $\mathrm{ClF} 1$ and structure of the identified compound, ethyl gallate. Figure S2: Nuclear Magnetic Resonance (NMR) 13C spectrum of C1F1 and structure of the identified compound, ethyl gallate. Figure S3: Nuclear Magnetic Resonance (NMR) $1 \mathrm{H}$ spectrum of $\mathrm{C} 2 \mathrm{~F} 1$ and structure of the identified compound, gallic acid. Figure S4: calibration curves of the HPLC analysis of the isolated compounds and their straight-line equations. Figure S5: Nuclear Magnetic Resonance (NMR) $1 \mathrm{H}$ spectrum of C4F4-P and structure of the identified compound, isoorientin. Figure S6: Nuclear Magnetic Resonance (NMR) 13C spectrum of C4F4-P and structure of the identified compound, isoorientin. Figure S7: Correlation Spectroscopy (COSY) of C4F4-P. Figure S8: Heteronuclear Single Quantum Coherence Spectroscopy (HSQC) of C4F4-P. Figure S9: Heteronuclear Multiple Bond Correlation Spectroscopy (HMBC) of C4F4-P. (Supplementary Materials)

\section{References}

[1] M. C. Riddle, "Basal glucose can be controlled, but the prandial problem persistsdit's thenext target," Diabetes Care, vol. 40, no. 3, pp. 291-300, 2017.

[2] M. A. Esquivel and M. C. Lansang, "Optimizing diabetes treatment in the presence of obesity," Cleveland Clinic Journal of Medicine, vol. 84, no. 1, pp. S22-S29, 2017. 
[3] V. Shettar, S. Patel, and S. Kidambi, "Epidemiology of Obesity and Pharmacologic Treatment Options," Nutrition in Clinical Practice, vol. 32, no. 4, pp. 441-462, 2017.

[4] U. Ghani, "Re-exploring promising $\alpha$-glucosidase inhibitors for potential development into oral anti-diabetic drugs: finding needle in the haystack," European Journal of Medicinal Chemistry, vol. 103, pp. 133-162, 2015.

[5] R. S. Padwal and S. R. Majumdar, "Drug treatments for obesity: orlistat, sibutramine, and rimonabant," The Lancet, vol. 369, no. 9555, pp. 71-77, 2007.

[6] L. J. Cumana-Campos, "Clave para especies de Ludwigia L. (Onagraceae) de la regi $\leq$ n nor-oriental e insular de Venezuela depositadas en el herbario IRBR," Acta Bot. Venez, vol. 33, no. 2, pp. 299-327, 2010.

[7] "SEMARNAT, 'Norma Oficial Mexicana NOM-059SEMARNAT-2010, Protección ambiental-Especies nativas de México de flora y fauna silvestres-Categorías de riesgo y especificaciones para su inclusión, exclusión o cambio-Lista de especies en riesgo., Diario Oficial de la Federación. Mexico, pp. $1-78,2006 "$.

[8] T. Murugesan, S. Sinha, M. Pal, and B. Saha, "Review on Phytochemical and Medicinal Aspects of Jussiaea Suferuticosa Linn," Ancient Science of Life, vol. 21, no. 3, pp. 205-207, 2002.

[9] "UNAM, Atlas de las Plantas de la Medicina Tradicional Mexicana, Biblioteca Digital de la Medicina Tradicional Mexicana," http://www.medicinatradicionalmexicana.unam.mx/atlas.php.

[10] G. Ramírez, M. Zavala, J. Pérez, and A. Zamilpa, "In vitro screening of medicinal plants used in Mexico as antidiabetics with glucosidase and lipase inhibitory activities," EvidenceBased Complementary and Alternative Medicine, vol. 2012, pp. $1-6,2012$.

[11] M. H. Khan and P. S. Yadava, "Antidiabetic plants used in Thoubal district of Manipur, Northeast India," Indian Journal of Traditional Knowledge, vol. 9, no. 3, pp. 510-514, 2010.

[12] H. Kadum Yakob, A. Manaf Uyub, and S. Fariza Sulaiman, "Toxicological evaluation of $80 \%$ methanol extract of Ludwigia octovalvis (Jacq.) P.H. Raven leaves (Onagraceae) in BALB/c mice," Journal of Ethnopharmacology, vol. 142, no. 3, pp. 663668, 2012.

[13] J. E. Averett, E. M. Zardini, and P. C. Hoch, "Flavonoid systematics of ten sections of Ludwigia (Onagraceae)," Biochemical Systematics and Ecology, vol. 18, no. 7-8, pp. 529-532, 1990.

[14] C.-I. Chang, C.-C. Kuo, J.-Y. Chang, and Y.-H. Kuo, “Three New Oleanane-Type Triterpenes from Ludwigia octovalvis with Cytotoxic Activity against Two Human Cancer Cell Lines," Journal of Natural Products, vol. 67, no. 1, pp. 91-93, 2004.

[15] J. Yan and X. W. Yang, "Studies on the chemical constituents in herb of Ludwigia octovalvis," China Journal of Chinese Materia Medica, vol. 30, no. 24, pp. 1923-1926, 2005.

[16] W.-S. Lin, J.-Y. Chen, J.-C. Wang et al., “The anti-aging effects of Ludwigia octovalvis on Drosophila melanogaster and SAMP8 mice," AGE, vol. 36, no. 2, pp. 689-703, 2014.

[17] W.-S. Lin, J.-H. Lo, J.-H. Yang et al., "Ludwigia octovalvis extract improves glycemic control and memory performance in diabetic mice," Journal of Ethnopharmacology, vol. 207, pp. 211219, 2017.

[18] S.-J. Wu, L.-T. Ng, G.-H. Wang, Y.-J. Huang, J.-L. Chen, and F.M. Sun, "Chlorophyll a, an active anti-proliferative compound of Ludwigia octovalvis, activates the CD95 (APO-1/CD95) system and AMPK pathway in 3T3-L1 cells," Food and Chemical Toxicology, vol. 48, no. 2, pp. 716-721, 2010.
[19] T. Murugesan, L. Ghosh, K. Mukherjee, J. Das, M. Pal, and B. P. Saha, "Evaluation of antidiarrhoeal profile of Jussiaea suffruticosa Linn. extract in rats," Phytotherapy Research, vol. 14, no. 5, pp. 381-383, 2000.

[20] H. Wagner and S. Bladt, 'Flavonoid Drugs', in Plant drug analysis: A Thin Layer Chromatography Atlas, Springer-Verlag, Berlin, Germany, 2nd edition, 1996.

[21] “The Plant List," http://www.theplantlist.org/.

[22] G. Ramirez, A. Zamilpa, M. Zavala, J. Perez, D. Morales, and J. Tortoriello, "Chrysoeriol and other polyphenols from Tecoma stans with lipase inhibitory activity," Journal of Ethnopharmacology, vol. 185, pp. 1-8, 2016.

[23] T. J. Mabry, K. R. Markham, and M. B. Thomas, Reagents and procedures for the Ultraviolet Spectral Analysis of Flavonoids, Springer Berlin Heidelberg, Heidelberg, Germany, 1st edition, 1970.

[24] S. Uzuner and D. Cekmecelioglu, "A rapid screening approach to factors affecting dilute acid hydrolysis of hazelnut shells," International Proceedings of Chemical, Biological \& Environmental Engineering, vol. 50, pp. 180-185, 2013.

[25] J. Peng, G. Fan, Z. Hong, Y. Chai, and Y. Wu, "Preparative separation of isovitexin and isoorientin from Patrinia villosa Juss by high-speed counter-current chromatography," Journal of Chromatography A, vol. 1074, no. 1-2, pp. 111-115, 2005.

[26] H. Bisswanger, 'Enzyme Kinetics', in Enzyme kinetics: Principles and Methods, Ringgold Inc, Portland, Ore, USA, 2nd edition, 2008.

[27] D. S. H. Bell, J. H. O'Keefe, and P. Jellinger, "Postprandial dysmetabolism: the missing link between diabetes and cardiovascular events?" Endocrine Practice, vol. 14, no. 1, pp. 112-124, 2008.

[28] T. Shiraiwa, H. Kaneto, T. Miyatsuka et al., "Postprandial hyperglycemia is a better predictor of the progression," Diabetes Care, vol. 28, no. 11, pp. 2806-2807, 2005.

[29] G. Derosa and P. Maffioli, " $\alpha$-Glucosidase inhibitors and their use in clinical practice," Archives of Medical Science, vol. 8, no. 5, pp. 899-906, 2012.

[30] M. P. Hermans, "Diabetes and the endothelium," Acta clinica Belgica, vol. 62, no. 2, pp. 97-101, 2007.

[31] A. Gastaldelli, M. Gaggini, and R. A. DeFronzo, "Role of adipose tissue insulin resistance in the natural history of type 2 diabetes: Results from the san antonio metabolism study," Diabetes, vol. 66 , no. 4 , pp. 815-822, 2017.

[32] M. Brownlee, "The pathobiology of diabetic complications: a unifying mechanism," Diabetes, vol. 54, no. 6, pp. 1615-1625, 2005.

[33] J. Kim and K. Yoon, "Glucolipotoxicity in Pancreatic $\beta$-Cells," Diabetes \& Metabolism Journal, vol. 35, no. 5, pp. 444-450, 2011.

[34] K. C. B. Tan, A. W. K. Tso, S. C. F. Tam, R. W. C. Pang, and K. S. L. Lam, "Acute effect of orlistat on post-prandial lipaemia and free fatty acids in overweight patients with Type 2 diabetes mellitus," Diabetic Medicine, vol. 19, no. 11, pp. 944-948, 2002.

[35] J. B. Reitsma, M. C. Cabezas, T. W. A. de Bruin, and D. W. Erkelens, "Relationship between improved postprandial lipemia and low-density lipoprotein metabolism during treatment with tetrahydrolipstatin, a pancreatic lipase inhibitor," Metabolism, vol. 43, no. 3, pp. 293-298, 1994.

[36] K. Tadera, Y. Minami, K. Takamatsu, and T. Matsuoka, "Inhibition of $\alpha$-glucosidase and $\alpha$-amylase by flavonoids," Journal of Nutritional Science and Vitaminology, vol. 52, no. 2, pp. 149-153, 2006. 
[37] H. Li, F. Song, J. Xing, R. Tsao, Z. Liu, and S. Liu, "Screening and Structural Characterization of $\alpha$-Glucosidase Inhibitors from Hawthorn Leaf Flavonoids Extract by Ultrafiltration LCDAD-MSn and SORI-CID FTICR MS," Journal of The American Society for Mass Spectrometry, vol. 20, no. 8, pp. 1496-1503, 2009.

[38] S. V. Reddy, A. K. Tiwari, U. S. Kumar, R. J. Rao, and J. M. Rao, "Free radical scavenging, enzyme inhibitory constituents from antidiabetic ayurvedic medicinal plant Hydnocarpus wightiana blume," Phytotherapy Research, vol. 19, no. 4, pp. 277-281, 2005.

[39] S. Ochir, M. Nishizawa, B. Jae Park et al., "Inhibitory effects of Rosa gallica on the digestive enzymes," Journal of Natural Medicines, vol. 64, no. 3, pp. 275-280, 2010.

[40] O. Kamiyama, F. Sanae, K. Ikeda et al., "In vitro inhibition of $\alpha$ glucosidases and glycogen phosphorylase by catechin gallates in green tea," Food Chemistry, vol. 122, no. 4, pp. 1061-1066, 2010.

[41] A. Ishikawa, H. Yamashita, M. Hiemori et al., "Characterization of inhibitors of postprandial hyperglycemia from the leaves of Nerium indicum," Journal of Nutritional Science and Vitaminology, vol. 53, no. 2, pp. 166-173, 2007.

[42] A. Kam, K. M. Li, V. Razmovski-Naumovski et al., "A comparative study on the inhibitory effects of different parts and chemical constituents of pomegranate on $\alpha$-amylase and $\alpha$ glucosidase," Phytotherapy Research, vol. 27, no. 11, pp. 16141620, 2013.

[43] L. Kakarla, S. Katragadda, A. Tiwari et al., "Free radical scavenging, $\alpha$-glucosidase inhibitory and anti-inflammatory constituents from Indian sedges, Cyperus scariosus R.Br and Cyperus rotundus L," Pharmacognosy Magazine, vol. 12, supplement 4, no. 47, pp. S488-S496, 2016.

[44] J. Li, Y. Lu, X. Su et al., "A norsesquiterpene lactone and a benzoic acid derivative from the leaves of Cyclocarya paliurus and their glucosidase and glycogen phosphorylase inhibiting activities," Planta Medica, vol. 74, no. 3, pp. 287-289, 2008.

[45] J. D. Wansi, M.-C. Lallemand, D. D. Chiozem et al., " $\alpha$ Glucosidase inhibitory constituents from stem bark of Terminalia superba (Combretaceae)," Phytochemistry, vol. 68, no. 15, pp. 2096-2100, 2007.

[46] N. Gupta, S. Gupta, and A. Mahmood, "Gallic acid inhibits brush border disaccharidases in mammalian intestine," Nutrition Research, vol. 27, no. 4, pp. 230-235, 2007.

[47] T. Oki, T. Matsui, and Y. Osajima, "Inhibitory effect of $\alpha$ glucosidase inhibitors varies according to its origin," Journal of Agricultural and Food Chemistry, vol. 47, no. 2, pp. 550-553, 1999.

[48] A. I. Martinez-Gonzalez, Á. G. Díaz-Sánchez, L. A. De La Rosa et al., "Polyphenolic compounds and digestive enzymes: In vitro non-covalent interactions," Molecules, vol. 22, no. 4, article no. 669, 2017.

[49] G.-N. Kim, M.-R. Shin, S. H. Shin et al., "Study of Antiobesity Effect through Inhibition of Pancreatic Lipase Activity of Diospyros kaki Fruit and Citrus unshiu Peel," BioMed Research International, vol. 2016, Article ID 1723042, pp. 1-7, 2016.

[50] L. Liu, Y.-L. Yu, J.-S. Yang et al., "Berberine suppresses intestinal disaccharidases with beneficial metabolic effects in diabetic states, evidences from in vivo and in vitro study," NaunynSchmiedeberg's Archives of Pharmacology, vol. 381, no. 4, pp. 371381, 2010. 


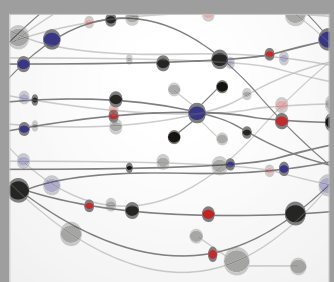

The Scientific World Journal
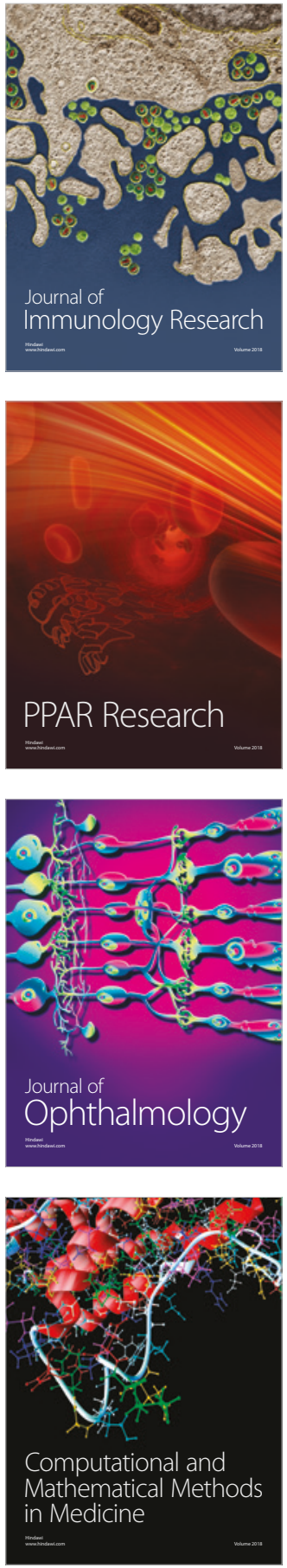

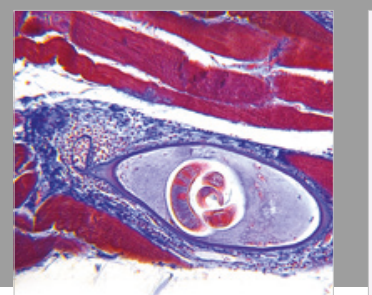

Gastroenterology Research and Practice

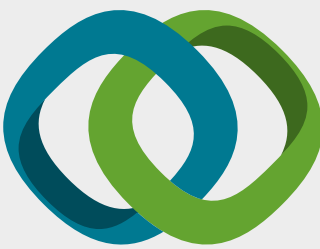

\section{Hindawi}

Submit your manuscripts at

www.hindawi.com
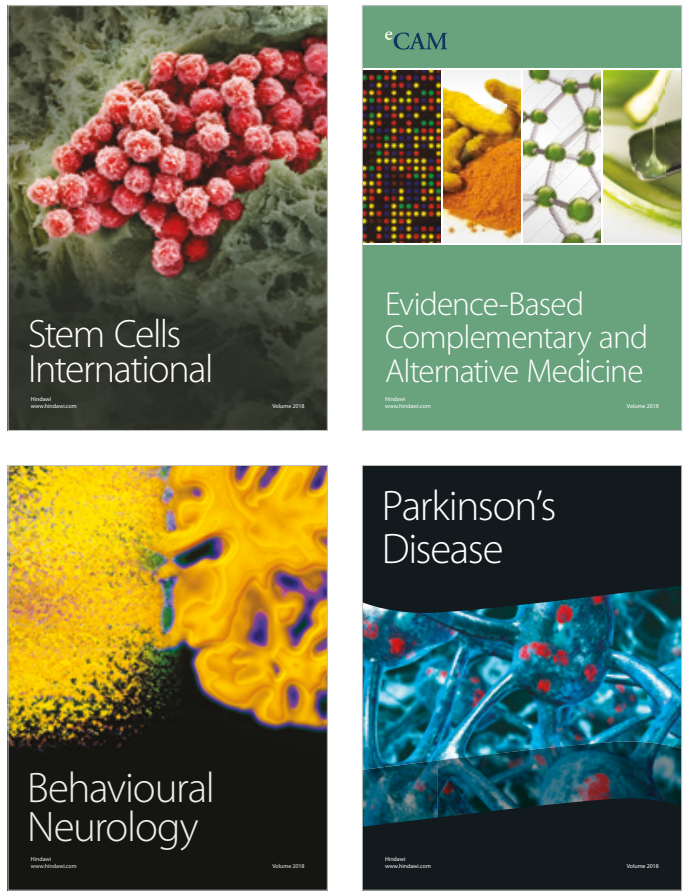

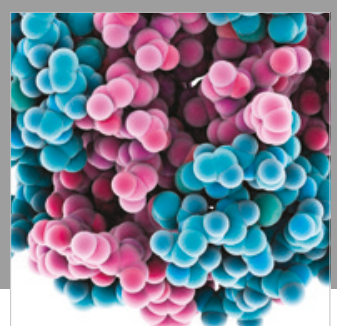

ournal of

Diabetes Research

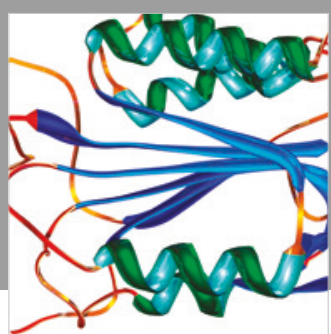

Disease Markers
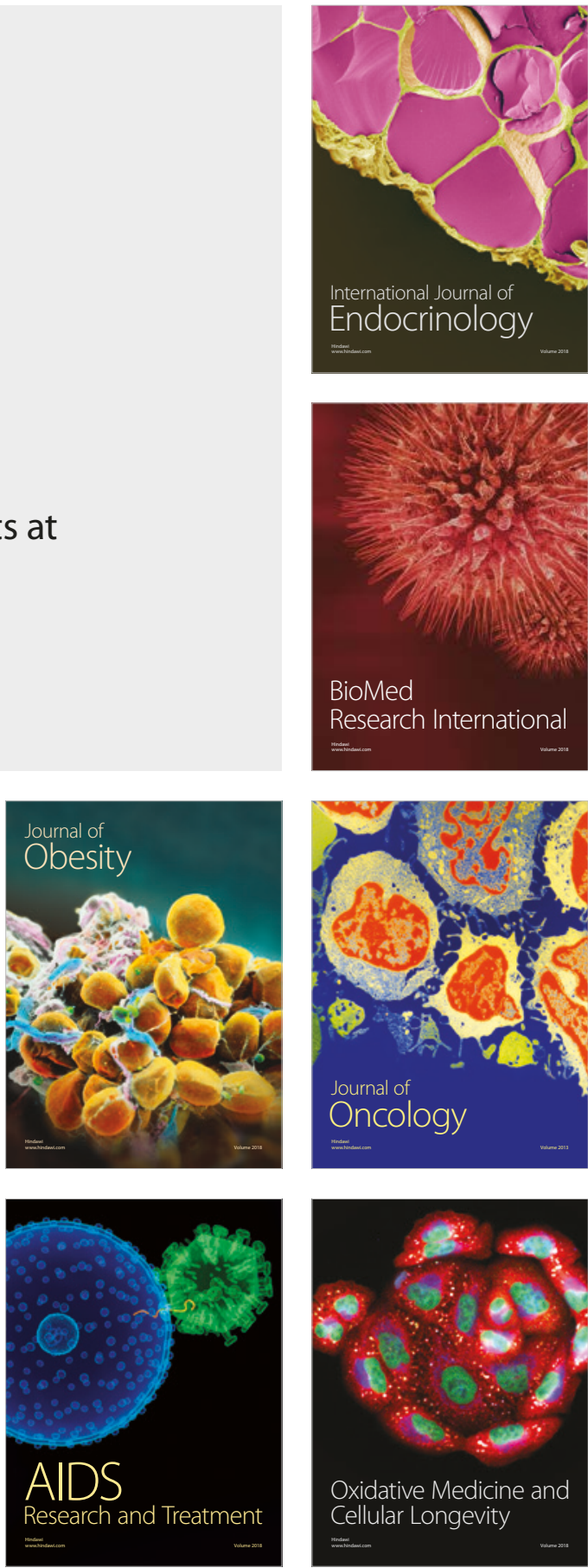